\title{
Gustave Flaubert'in Madame Bovary Adlı Fransızca Romanının İngilizce ve Türkçe Çevirilerinin Eşdeğerlik Bağlamında Karşıllaştırmalı Olarak İncelenmesi
}

\section{A Comparison of Gustave Flaubert's French Novel Madame Bovary in The Equivalence of English and Turkish Translations}

\author{
Murat Özcan ${ }^{1}$ (), Aslı Çelik² (1)
}

'Doç. Dr., Ankara Hacı Bayram Veli Üniversitesi, Edebiyat Fakültesi, Arapça Mütercim Tercümanlık, Ankara, Türkiye

${ }^{2}$ Doktora Öğrencisi, Ankara Hacı Bayram Veli Üniversitesi, Mütercim Tercümanlık, Çeviri ve Kültürel Çalışmalar, Ankara, Türkiye

ORCID: M.Ö. 0000-0001-8578-119X A.Ç. 0000-0001-7003-1505

Sorumlu yazar/Corresponding author: Aslı Çelik (Doktora Öğrencisi), Ankara Hacı Bayram Veli Üniversitesi, Mütercim Tercümanlık, Çeviri ve Kültürel Çalışmalar, Ankara, Türkiye

E-mail: asli.celik@hbv.edu.tr;

aslicelikfr@gmail.com

Başvuru/Submitted: 26.10 .2021 Kabul/Accepted: 29.12 .2021

Atıf/Citation: Ozcan, M., Celik, A. (2021). Gustave Flaubert'in Madame Bovary adlı Fransızca romanının İngilizce ve Türkçe çevirilerinin eşdeğerlik bağlamında karşılaştırmalı olarak incelenmesi. Istanbul Üniversitesi Çeviribilim Dergisi - Istanbul University Journal of Translation Studies, 15, 75-91. https://doi.org/10.26650/iujts.2021.1015094

\section{öz}

Toplumların kültür farkları, yaşama ve düşünce biçimlerindeki farklılıklar dillerine yansır. Böylece her dil bünyesinde kendine özgü özellikler bulundurur. Bir toplumun sahip olduğu kültürel birikim çeviri için önemli bir bileşendir. Çevirinin kültürden kültüre gerçekleşen bir eylem olması dillere yansıyan özelliklerin başka dilde dengini bulmayı gerekli hale getirir. Çeviri metnin işlevsel olabilmesi kaynak kültürün doğru alımlanmasına ve erek kültürü de göz önünde bulundurmaya bağlıdır. Bundan dolayı çeviri eyleminin hem dilbilimsel, anlamsal ve biçimsel özelliklere hem de kültürel unsurlara dikkat edilerek gerçekleştirilmesi beklenir. Bu bağlamda algılanan kaynak kültürün her iki erek kültürde nasıl yansıdığını ortaya koymak çalışmanın başlangıç noktasını oluşturmaktadır. Bu çalışma Gustave Flaubert'in "Madame Bovary" adlı romanından seçilen örneklerin İngilizce ve Türkçe çevirileri ile eşdeğerlik kuramına bağı kalarak karşılaştırmalı bir biçimde incelenmesini içerir. Betimleyici yöntem temelinde karşılaştırmalı olarak yapılan çalışmanın amacı eşdeğerliğin sağlanmasında kültürlerin etkisini ortaya koymaktır.

Anahtar kelimeler: Çeviri, yazın çevirisi, çeviride eşdeğerlik, kültürel unsurlar, çeviri karşılaştırması

\section{ABSTRACT}

The cultural differences between the Turkish, English, and French societies and the differences in their respective ways of life and thought processes are reflected in their respective languages. Therefore, each language has its own features. The cultural accumulation of a society is a vital factor in translation. Translation takes typically involves the expression of text not only in a different (target) language but also a different cultural context; thus, during the translation process, it is essential to identify the equivalent features of the source language of the text in the target language. The functionality of the translated text depends upon the accuracy with which the source culture is perceived and the target culture acknowledged. Therefore, the act of translation must consider the semantic and formal characteristics of the languages as well as the formal and cultural elements of both cultures. In this context,this study examines the ways in which the perceived source culture is reflected in both the target cultures. This study 
entails a comparative analysis of examples selected from Gustave Flaubert's novel Madame Bovary using their English and Turkish translations within the framework of equivalence theory. The aim of this comparative study-which employs the descriptive method-is to reveal the effect of cultures on ensuring equivalence.

Keywords: Translation, literary translation, equivalence in translation, cultural elements, contrasting translations

\section{EXTENDED ABSTRACT}

\section{Research Problem}

This study seeks to explore the extent to which equivalence is achieved in the English and Turkish translations of Gustave Flaubert's French novel Madame Bovary. Because translation involves a linguistic transfer while also serving as an intercultural activity, the reflections of the source text in the target languages have been emphasized in this study. In addition, the relationship between translation and culture has been evaluated by means of studying a text with French as the source language vis-à-vis its English and Turkish translations, i.e., the target texts. The culture of the text in any language is presented to the target reader by the translators of that text. Therefore, the preferences of each translator are shaped according to the lifestyles and cultural values of the society in which they live. This study aims to analyze two evidently distinct target languages as well as cultures. It also derives interpretations based on common or different expressions originating from such distinct languages and cultures. Because translators typically carry out the translation process by either preserving source text expressions or adapting them in the target language, the author discusses expressions wherein source text expressions are preserved or adapted.

\section{Research Questions}

Have the cultural elements in the source language been transferred in accordance with the reception of the text by the target audience during the translation process? How can translator preferences in both languages be evaluated? Do the translators prefer a linguistic or cultural translation? Do cultural differences require significant changes in the source text for better understandability? This article is an attempt to answer these questions.

\section{Literature Review}

Various opinions have been proposed with regard to establishing an equivalence between the source and target texts in the translation process. Among the current theories is the equivalence theory, which entails the views of pioneer theorists in the field.

This study analyzes Madame Bovary (1857), a notable novel by Gustave Flaubert, who was the pioneer of the realist movement. To this end, the author considers the novel's English and Turkish translations carried out by professional translators. The study entails a comparative analysis of the Turkish and English translations. It is important to remember that the translation process is inextricably linked to cultural influences. Turkish and English languages as well as 
cultures are significantly different, which necessitates different choices by translators during the translation process.

In this context, there are many studies in the national and international literature that include translation comparisons. In general, the comparison of translations in two different languages and cultures necessitates the establishment of equivalence. Therefore, this article is a study with the theory of equivalence in transferring to different cultures. The respective translators have considered both British and Turkish cultures in the translation process.

\section{Methodology}

The author discusses the source text in the context of both translations by comparing translations through the descriptive method. This study uses the document analysis method, which aims to evaluate Gustave Flaubert's Madame Bovary by comparing the texts translated into English and Turkish in the context of the equivalence translation theory. Since equivalence theory in translation constitutes the theoretical framework that guides the comparative analysis, equivalence theories proposed by different theorists are examined in detail. The section wherein source and target texts are analyzed comparatively reveals that equivalence leads to translators using target-oriented or source-oriented translation. Culture, which has an important place in the translation process, contains and reflects each society's unique historical accumulation and social characteristics.

For this reason, translations appropriate to the target audience should be preferred in the translation process. In both translations, the preference of the translators and their reflections in the target languages are emphasized. In qualitative research, interpretations and descriptions are made based on the findings obtained through document analysis. During the analysis, the translated texts are examined in detail. Translators' preferences are evaluated, and explanations are made about how much equivalence is achieved.

\section{Results and Conclusions}

Language and culture are two dominant factors during the translation process. The translators must overcome both linguistic and cultural obstacles. The author concludes that the concept of equivalence should be defined as equivalence according to the target audience. While creating target texts, the paper emphasizes that semantic protection of the source text is the primary and ultimate goal. Thus, focusing on the target language readers to ensure that they understand the text message correctly is critical.

While transferring the linguistic data of the original text to the target language, the differences between the source language and the target language limit the possibilities of a literal translation. Accordingly, translators in both languages aim at intelligibility for the target language reader. The author demonstrates how each translation is actually a re-enactment or re-creation of the original. In this study, the possible contributions of questioning and interpreting how the 
information conveyed from the original text is translated in these revived texts is explained in the field of translation studies. The author concludes that it is necessary to view the text translated into a different culture as a new text and to the translator as a new perspective. Although translated works always depend on the source text, they become texts that re-exist in the language into which they were translated. Further, comparing the analyzed text with its translations in two different languages makes it possible to see the role of culture in the translation process in a comparative way.

This study reveals that it is impossible to ignore language independent of culture. The author has endeavored to put forward certain ideas within the framework of equivalence theory. The paper concludes that in the equivalence theory, the translator has a guiding theory in terms of translating according to target culture norms. 


\section{Giriş}

Çeviri, farklı dillerin ortaya çıkmasıyla birlikte var olmuş yüzyıllardır devam eden bir etkinliktir. İnsanların ihtiyaçları ile aynı doğrultuda gelişme gösteren çeviri etkinliği yazın, ticari, siyasi ve hukuki gibi birçok alanda gelişme gösteren zorunlu bir ihtiyaç halini almıştır.

İngilizcede "translation”, Fransızcada "traduction” sözcükleri ile ifade edilen çeviri kavramı Kuran'a göre “dar anlamıyla bir yazın yapıtını şekil, anlam, ileti ve biçem düzeylerinde kaynak dilden amaç dile aktarma, geniş anlamıyla ise, bir kültür ürününü, başka bir kültürün alımlamasına sunma, hatta bu ürünün amaç kültür dizgesi içinde bir yer edinmesine, o dizgedeki diğer eserlerle hesaplaşmasına zemin sağlamadır” (Kuran, 1993, s. 1). Çeviri, kısaca “diller ve kültürler arası bir aktarım" (Boztaş, 1992, s. 249) olarak ya da en genel anlamıyla "bütün çağlarda karşımıza çıkan bir etkinlik, çeşitli uygarlıklar arasında köprü kuran, değişik toplumlardan bireyleri birbirine yaklaştıran, her tür kültürel değeri, içinde oluşturduğu tarihsel ve toplumsal çevrenin dişına taşıyan, o çevreden olmayan kişilerin yararlanmasına sunan, uygarlıklar arası bir iletişim ve bildirişim aracı" (Vardar, 1981, s. 173) olarak tanımlanmaktadır.

Nida ve Taber çeviriyi “kaynak dildeki bir iletinin en doğal eşdeğerinin erek dilde yeniden üretilmesine dayanır” biçiminde tanımlamaktadır (Nord, 2008, s. 18). Lederer (1994, s. 11) çeviriyi, “çıkış/kaynak metnini anlamak, anlamı dilbilgisel biçiminden sıyırmak ve anlaşılan anlamları ve metnin uyandırdığ 1 duyguları öteki dilde ifade etmek" biçiminde tanımlar. Dolayısıyla kaynak dildeki metnin vermek istediği anlam doğru anlaşılmalı ve anlamsal değeri korunarak erek dilde o anlam yorumlanıp tekrar oluşturulmalıdır. Önemli olan anlamın doğru ve anlaşılır bir biçimde aktarılabilmesidir. Dolayısıyla bir dilde yer alan iletinin diğer dilde anlamsal olarak eşdeğer olma eğiliminde olması beklenir. Çeviriyi, kaynak dilde yer alan bir metnin erek dile dilbilgisel, anlamsal ve biçimsel aktarımı olarak nitelendirmek mümkündür. $\mathrm{Bu}$ doğrultuda çeviri için duygu, düşünce ya da anlamın bir dilden başka bir dile aktarımı ve erek dilde metnin yeniden oluşturulması biçiminde genel bir ifade kullanılabilir. Kısacası çeviri, başka bir dile aktarılan metni her yönüyle o dilde anlaşılabilir hale getirmektir.

Bu çalışmanın öncelikli amacı, 19. yüzyıl Fransız Edebiyatında realizm akımının temsilcilerinden Gustave Flaubert tarafindan kaleme alınan Madame Bovary’nin (1857), İngilizce ve Türkçe çevirilerinde eşdeğerliğin ne ölçüde sağlandığını araştırmaktır. Bu doğrultuda çalışmanın kuramsal çerçevesini oluşturan eşdeğerlik kuramı hakkında öncü kuramcılar tarafından ortaya atılan görüşlere yer verilmektedir.

Madame Bovary adlı eseri, İngilizce ve Türkçe metinleri ile karşılaştırmalı olarak eşdeğer çeviri kuramı bağlamında değerlendirmeyi amaçlayan bu çalışmada doküman analizi yöntemi kullanılmıştır. Nitel araştırmalarda doküman incelemesi ile elde edilen bulgular üzerinden yorum ve betimlemeler yapılarak erek dil metinleri incelenmektedir. Bu doğrultuda çevirmenlerin tercihleri değerlendirilir ve ne kadar eşdeğer metinler ortaya koydukları konusunda açıklamalar yapılır. Çeviri hem dilsel bir aktarım hem de kültürlerarası bir eylem olduğundan kaynak metnin erek dillerdeki yansımaları üzerinde durulur. Çeviri etkinliğini kültürden ayırmanın mümkün olmadığının altı 
çizilerek Türk ve İngiliz kültürlerinin de dilleri gibi farklı olması, çeviri sürecinde çevirmenlerin farklı seçimler yapmasını zorunlu kılmıştır. Her çevirmenin tercihi, içinde yaşadığı toplumun yaşam tarzına ve kültürel değerlerine göre şekillenebilmektedir. Ancak erek metinler oluşturulurken kaynak metnin anlamsal olarak korunmasının çevirmenler için birincil amaç olmasının yanı sıra çevirmenlerin erek dil okuyucusu için anlaşılırlığı amaçlamaları da gerekmektedir. Özgün metnin dilsel verileri erek dile aktarılırken, kaynak dil ile erek dil arasındaki farklılıklar, bazı durumlarda sözcüklerin tam anlamıyla çeviri imkânını sınırlandırabilir. Dolayısıyla çevirmenler çeviri sürecinde hem dilsel hem de kültürel engellerin üstesinden gelebilmelidir.

Bu çalışma, dilin kültürden bağımsız düşünülemeyeceğini ortaya koyarak eşdeğerlik kuramı çerçevesinde karşılaştırmalı bir analiz içermektedir. Türk ve İngiliz kültürleri birbirinden farklı olduğundan hem farklı diller hem de iki farklı kültür hakkında bazı bulgular elde edilmesi de amaçlar arasında yer almaktadır. Çeviri sürecinde kaynak dildeki kültürel unsurlar, metnin erek kitle tarafından algılanmasına uygun bir biçimde aktarılmış mı? Her iki dilde de çevirmen tercihleri nasıl değerlendirilebilir? Çevirmenler dilsel çeviriyi mi yoksa kültürel çeviriyi mi tercih etmektedirler? Kültürel farklılıklar, erek okuyucunun metni anlaması için önemli değişiklikler gerektiriyor mu? şeklinde birtakım sorulara cevaplar aranmaktadır. Çeviri ve kültür ilişkisi Fransızca kaynak metin ve İngilizce, Türkçe erek metinler üzerinden değerlendirilirken dillerin ve kültürlerin farklılıklarından kaynaklanan yorumlara da yer verilmektedir. Her iki erek dilde de çevirmenlerin tercihleri, hangi ifadeleri koruyarak ya da hangilerini uyarlayarak erek dile aktardıkları tartışılmaktadır. Kaynak ve erek metinlerin karşılaştırmalı olarak incelendiği bölümde eşdeğerliğin çevirmenleri erek odaklı mı yoksa kaynak odaklı mı çeviriye yönlendirdiği ortaya koyulmaktadır. İncelenen metnin iki farklı dildeki çevirileriyle karşılaştırılması, kültürlerin çeviri sürecindeki rolünü karşılaştırmalı bir biçimde görmeyi mümkün kılar.

\section{1. Çeviride Eşdeğerlik Kuramı}

Latince eşit, benzer anlamına gelen "aequalis" sözcüğünden İngilizceye "equivalence" biçiminde geçen sözcük dilimizde "eşdeğerlik" yani "aynı değerde olma”, "eşitlik" gibi karşılıklarla kullanılmaktadır (Çavuş, 2005, s. 66). Belirli (doğal) bir dille yazılmış bir yapıtta bildirilmek istenilenin başka bir dille iletilmesi biçiminde ifade edilebilen çeviri eyleminde asıl metindeki anlamı aktarmak esastır. Çeviride eşdeğerlik kavramında ise hem içerik hem de biçim yönünden en az anlam kaybı ile başka bir dile aktarım söz konusudur. Kaynak dil ile erek dil arasında yeterli düzeyde bir denklik kurma ve iletinin erek dile en uygun biçimde yansıtma işlemi olduğu da anlaşılmaktadır. Eşdeğerlik için kaynak dildeki mesajın anlamsal ve kültürel bağlamda en doğal biçimde aktarılabilme becerisi olduğunu söylemek mümkündür. Kaynak dil kültüründe var olan inanış ve gelenekler ya da bazı özel ifadeler erek dil kültürünün uzak olduğu ya da tanımadığı ifadeler olabilmektedir. Burada çevirmenin eşdeğerlik sağlamadaki becerisi önem içerir. Yirminci yüzyılın ikinci yarısından itibaren eşdeğer çeviri tartışmasında daha sistematik çeviri kuramları oluşturmak amaçlanmıştır. Çeviribilim kuramcılarından 
birçoğu eşdeğerlik kavramına farklı yaklaşım ve bakış açısı geliştirmiştir. Bunlardan bazılarının eşdeğerlik kavramına yaklaşımlarından bahsedilmektedir.

Vinay ve Darbelnet (1995, s. 38) eşdeğerliği kaynak metindeki ifadenin tamamen farklı sözcüklerle erek dilde tekrar edilmesi süreci olarak belirtir. Vinay ve Darbelnet'e göre kaynak dildeki metnin durumuna çevirmen bir çözüm bulmalıdır. Kaynak metinde bir ifadenin anlamsal olarak eşdeğerinin sözlükte bulunması başarılı bir çeviri için yeterli değildir. Örnek olarak İngilizcede yer alan "take one" (birini al) ifadesini vererek Fransızcada eşdeğerliği "prenez-en un" ifadesini verir. Ancak bu ifade bir market standında not olarak asılmışsa çevirmen eşdeğer terim olarak "echantillon gratuit" ifadesini tercih edecektir (Vinay \& Darbelnet, 1995, s. 256). Eugene Nida, eşdeğerliğin hem biçim bakımından hem de üslup (biçem) ve anlam bakımından da sağlanmasının gereklikliliğini vurgular. Nida, biçimsel eşdeğerlik ve dinamik eşdeğerlik olmak üzere iki tür eşdeğerlikten bahseder. Biçimsel eşdeğerlik, mesaja hem biçim hem de içerik yönünden odaklanır (Nida, 1964, s. 159). Biçimsel eşdeğerlik sağlamayı amaçlayan çeviride şiir sanatı şiir sanatına, tümce tümceye, kavram kavrama aktarılırken karşılıklar bulmanın yolları araştırılır. Biçimsel eşdeğerlik, kaynak dildeki dilbilgisel, sözcüksel ve anlamsal yapıları erek dile en yakın eşdeğeri ile aktarmayı ifade eder (Nida, 1964, s. 165-166). Çeviri konusunda değiştirim (substitution) yaklaşımını savunan John Catford (1965), "çeviride, erek dil anlamlarının kaynak dil anlamları ile yer değiştirdiğini, kaynak dil anlamlarının erek dile aktarılmadığını" (1965, s. 20) ileri sürmektedir. "Çeviride, kaynak dil ve erek dil metinleri, belli bir durumda tüm öğeleri ile karşılıklı olarak değiştirilebilir olduğunda çeviri eşdeğer bir çeviridir” (Catford, 1965, s. 49). Eşdeğerliğin önemi bazen biçim bazen de içerik yönünden vurgulandığı görülmektedir. Popoviç biçimsel eşdeğerlik üzerinde dururken, Kade (1968) eşdeğerliğin içerik düzeyinde değişmezi aktarmakla sağlanacağını ileri sürer. Özellikle yazılı metinlerde içerikle biçim iç içe bulunur ve birbirini tamamlar. Dolayısıyla bu tür tanımlamalar eksik kalmaktadır. Biçim, metni oluşturan unsurlardan sadece bir tanesi iken içerik dil bağlamı içinde, bir iletişim ortamında ve tarihin bir yerinde hep bulunmaktadır ve ayrı olarak ele alınmamaktadır (Köksal, 2008, s. 36). Çeviride eşdeğerliği Popoviç dilsel eşdeğerlik, dizisel eşdeğerlik, biçimsel eşdeğerlik, metinsel (dizimsel) eşdeğerlik olmak üzere dört sınıflandırmada ele alır. Dilsel eşdeğerlikte kaynak ve erek metinlerin dilsel düzeyindeki benzerliği; dizisel eşdeğerlikte öğelerin eşdeğerliği; biçimsel eşdeğerlikte anlatım benzerliği, kaynak ve erek metindeki öğerin işlevsel eşdeğerliği; metinsel (dizimsel) eşdeğerlikte şekil eşdeğerliğinden bahsedilir. Yazıcı (2005: 84), Popoviç'in öne sürdüğü eşdeğerlikle ilgili tanımların aşamalı olarak çeviride eşdeğerliği sağlamak üzere birbiriyle bağlantı içinde olduğunu belirtir. Biçimsel eşdeğerliliğe ulaşmada dilsel eşdeğerlik en alt sırada yer alırken dizisel eşdeğerliğin onun üzerinde yer aldığını ifade eder. Popoviç’in çeviride biçemi eşdeğerlik ölçütü olarak seçmesi çevirinin yazınsal alanda metinselliğinin önemine dikkat çektiği gibi onun erek ekin ürünü olarak anlatımsal kimliğini vurgulaması açısından da önem taşımaktadır. Wills (1977), eşdeğerlik kavramının iki farklı sistem öğeleri arasında bağdaşıklık (corelation) olduğu görüşünü ileri sürer. Nasıl ki matematiksel bir denklemde her iki taraftaki anlatımlar ya da miktar değiştirilebilirse çeviride de bu türden bir değiştirilebilirliğin mümkün olduğunu söyler. Mona 
Baker (1992), çeviride eşdeğerlik düzeylerini bir bütün olarak ele alır. Çevirinin neredeyse tüm farklı yönlerini farklı düzeylerde ortaya koymaktadır. Baker, eşdeğerliği dört grup halinde sınıflandırır: sözcük ve sözcük-üstü düzeyde eşdeğerlik, dilbilgisel eşdeğerlik, metinsel eşdeğerlik, kullanımsal eşdeğerlik. Sözcük ve sözcük-üstü düzeyde eşdeğerlik, bir dilden başka bir dile çeviri sırasında sözcük ve sözcük-üstü düzeyde görülen eşdeğerliktir. Çevirmen kaynak dili çözümlemeye başladığında metin ya da söylem gibi daha üst düzeylerle değil sözcüklerle karşı karşıyadır. Dolayısıyla çevirmen öncelikle sözcüksel düzeyi göz önünde bulundurmalıdır. Ancak çevirmen, sözcügü ele alırken sayı, cins ve zaman gibi bir çok faktöre dikkat etmek durumundadır. Sözcük-üstü düzeyde ise eşdizimler, kalıplaşmış ifadeler ve deyimler yer almaktadır (Baker, 1992, s. 11-12). Dilbilgisel eşdeğerlik düzeyinde dillerin dilbilgisel kategorileri arasındaki farklılığa dikkat çeker. Dillerin gramer kurallarının sık sık değişiklik göstermesi dilin doğrudan eşdeğerini erek dilde bulmayı zorlaştıran bir durumdur. Bu farklılıktan dolayı kaynak dildeki bilgi ya da mesaj erek dilde önemli ölçüde değişebilir. Çevirmen erek dilde bazı bilgileri eklemeyi ya da çıkarmayı tercih edebilir. Baker, sayı, zaman, görünüş, kip, şahıs ve cinsiyet konularını çeviride problem teşkil edebilen dilbilgisel araçlar arasında sıralar. Metinsel eşdeğerlik düzeyi, kaynak ve erek dildeki metinlerin bilgi ve tutarlık açısından eşdeğer olmasını ifade etmektedir. Çeviride önemli bir özellik olan metinsel doku, çevirmene özgül bir bağlamda erek kültür izleyicisi için bağlaşık ve bağdaşık bir metin üretme çabasında yardımcı olan kaynak metnin anlaşılmasında ve çözümlenmesinde yararlıdır (Baker, 1992, s. 212). Kullanımsal eşdeğerlik düzeyi, Suçin'in ifade ettiğine göre (2007), çeviri sürecinde sezdiriler ve kaçınma stratejilerine odaklanır. Çevirmen kaynak metinde üstü kapalı ifade edilen anlamları erek kitle için açık hale getirerek oluşturmalıdır. Roman Jakobson eşdeğerlik ile ilgili olarak "farklılıkta eşdeğerlik" (equivalence in difference) terimini kullanmıştır. Jakobson, eşdeğerlik kuramını Amerikan filozof ve matematikçi Charles Sanders Peirce'ın (1839- 1914) gösterge bilim yaklaşımı üzerinde temellendirerek "there is no signatum without signum" (Gösterilensiz gösterge yoktur) (Jakobson, 1959, s. 232) ile ifade eder. Jakobson, bu düşünce üzerinden çeviri türleri için üç sınıflandırma yapar: aynı dil içinde yeniden yorumlama ve açımlama biçiminde ifade ettiği diliçi (intralingual) çeviri; bir dildeki göstergelerin başka bir dildeki göstergelerle yorumlanması biçiminde ifade ettiği diller arası (interlingual) çeviri ve bir dildeki sözlü göstergelerin sözlü olmayan başka göstergelerle yorumlanması biçiminde ifade ettiği göstergeler arası (intersemiotic) çeviridir (Jakobson, 1959, s. 233). Peter Newmark anlamsal çeviri ve iletişimsel çeviri terimlerini kullanmayı tercih etmektedir. Genel anlamda anlamsal çeviri kaynak dil yazarının dili düzeyinde yazılırken iletişimsel çeviri okuyucunun dili düzeyinde yazılır. Anlamsal çeviri anlatımsal metinler, iletişimsel çeviri ise bilgilendirici ve çağrısal metinler için uygundur (Newmark, 1988, s. 47). Gideon Toury, eşdeğerlik için "işlevsel-gerçek" (functional-dynamic) ifadesini kullanır. Eşdeğerliğin dilbilimsel ağırlıklı olarak tanımlanmasının kaynak odaklı (source oriented), yönergeci (directive) ve kuralcı (normative) olarak sonuçlandığını belirtir ve bu tanımlarda yalnızca "doğru örneklerin" ve “türlerin” ele alındığının altını çizer (Toury, 1980, s. 39-40). Ayrıca Toury" nin eşdeğerlik kavramı farklılıklar ve diller arası yapısal ayrıma dayanır. Erek kültürün kabul edebilirliği (acceptability) 
ve kaynak metne olan yeterli uygunluk (adequacy) olarak adlandırılan iki kutubun tam ortasına çeviriyi yerleştirir. Ona göre hiçbir metin tamamen kabul edilebilirliğe ya da uygunluğa sahip olamayacaktır. Dolayısıyla çevirinin her seferinde katıldığı dizgeye yabancı gelecek biçimler ve bilgiler sunacağını ve çevirinin özgün metne de her zaman tamamen uygun olarak üretilemeyeceğini belirterek erek dilin ve kültürün kültüre özgü kurallarının kaynak metin yapılarında kaymalara yol açacağını da ifade eder. Bu açıdan ele alındığında çeviri eleştirisinin çevirmende hatalar bulmaya odaklandığı çünkü çeviri metnin her iki soyut kutbunda ideal ölçümleri tamamen karşılayamadığı görülür (Aksoy, 2002, s. 46-47).

\section{Eşdeğerlik Bağlamında "Madame Bovary" Adlı Romanın Fransızca Özgün Metin ile İngilizce ve Türkçe Çevirilerinin Karşılaştırmalı Olarak İncelenmesi}

Gustave Flaubert tarafından kaleme alınan Madame Bovary adlı romanda, çeviride eşdeğerlik kavramının irdelenmesi amacına yönelik olarak seçilmiş örnekler iki farklı dil ve kültürde kaynak metin ifadelerinin nasıl yorumlandığına yönelik kıyaslamalarla ele alınmaktadır. Çevirinin bir yorumlama sanatı olduğunu, ifadenin her dil ve kültürde farklı yorumlanabileceğini görmek bu sayede mümkün olmaktadır. Seçilmiş örnekler analiz edilerek romanın İngilizce ve Türkçe çevirilerinde ortaya çıkan genel prensipler değerlendirilmektedir. İki farklı dil ile karşılaştırmalı olarak çözümlemenin amacı, kaynak metindeki anlamların, farklı dil ve kültüre sahip çevirmenlerin tercihleri ışığında erek dilde nasıl yaratılabildiğini nedenleriyle ortaya koymaktır. Çevirmenin, erek okuyucu kitlesinin beklentisine ve kültürüne uygun olarak belirlediği çeviri yöntemine göre çeviri eylemini gerçekleştirmesi beklenir. Bu amaca yönelik çevirmenlerin tercihleri ve tutumları üzerinden bir inceleme yapılmaktadır.

Örn. 1. "Monsieur Roger, lui dit-il à demi-voix, voici un élève que je vous recommande, il entre en cinquième. Si son travail et sa conduite sont méritoires, il passera dans les grands, où l'appelle son âge" (Flaubert, 1929, s. 7).

“Monsieur Roger,' he said in a low voice, 'this is a pupil I'm putting in your hands. He's starting in the fifth. If his work and his conduct warrant it, he'll be moved up to the "seniors", which is where he should be, given his age.” (p. 5)
"Bu efendiye göz kulak olursunuz, Mösyö Roger, dedi. Beşinciye giriyor. Çalışması, ahlakı ile kendini beğendirirse, büyükler arasına, yaşına göre bir sınıfa çıkarırız.” (s. 21)

Kaynak metinde yer alan "voici un élève que je vous recommande" (sana önerdiğim işte bu çocuk) ifadesi İngilizce'de "this is a pupil I'm putting in your hands" (işte sana ilgilenmeni önerdiğim bir öğrenci) biçiminde kaynak metne bağlı olarak aktarılmışken, Türkçe'de "korunması gereken kimseyi ya da şeyi görüp gözetmek; görme, işitme yoluyla bilgi edinmeye çalışmak" (Aksoy,1988, s.811) anlamlarına gelen "göz kulak olmak" deyimi ile anlam aktarımının sağlandığı görülmektedir. Çevirmen bir deyimden yararlanmış ve anlamı erek kültüre özgü bir ifade ile sağlamıştır.

Örn. 2. "On commença la récitation des leçons. Il les écouta de toutes ses oreilles, attentif comme au sermon, n'osant même croiser les cuisses, ni s'appuyer sur le coude, et, à deux heures, quand la cloche sonna, le maître d'études fut obligé de l'avertir, pour qu'il se mît avec nous dans les rangs" (Flaubert, 1929, s. 8). 
"We began reciting our lessons. He listened

attentively, concentrat- ing as though listening to a sermon, not daring even to cross his legs or lean on his elbow, and, at two o'clock, when the bell rang, the master had to tell him to line up with us all." (p. 5)
"Kalkıp derslerimizi anlatmaya başladık. O, kilisede dinsel öğüt dinliyormuş gibi kulak kesildi; ayak ayak üstüne atmaya, dirseğine dayanmaya bile cesaret edemiyordu; saat ikiye gelip de zil çalınca, bizimle birlikte sıraya girmesi için, etüt öğretmeni kendisine seslenmek zorunda kaldı.” (s. 21)

Fransızca'da yer alan "dikkatli bir şekilde dinlemek" anlamına gelen "écouter de toutes ses oreilles" deyimi, İngilizce'de "listen attentively" (dikkatlice dinlemek) biçiminde aktarılmıştır. Türkçe çevirisinde ise "dikkatini vererek dinlemek" anlamında kullanılan "kulak kesilmek" deyimi kullanılarak erek kültüre özgü bir kullanımla anlam aktarımı sağlanmıştır.

Örn. 3. “Mais, soit qu'il n'eût pas remarqué cette manœuvre ou qu'iln'eût osé s'y soumettre, la prière était finie que le nouveau tenait encore sa casquette sur ses deux genoux" (Flaubert, 1929, s. 8-9).

"But, either because he had not noticed this manoeuvre or because he did not dare try it, prayers were over and the 'new boy' was still holding his cap on his knees.” (p. 5)

Kaynak metinde "cesaret etmek" fiili ile oluşturulan cümle, İngilizce'de de kaynak metne bağlı olarak yine "cesaret etmek" anlamına gelen "dare” fiili ile aktarılmıştır. Türkçe'de ise erek kültüre özgü bir deyim ile anlam aktarımı sağlandı̆̆ı görülmektedir.

Örn. 4. "Une fois marié, il vécut deux ou trois ans sur la fortune de sa femme, dînant bien, se levant tard, fumant dans de grandes pipes en porcelaine, ne rentrant le soir qu'après le spectacle et fréquentant les cafés" (Flaubert, 1929, s. 13).

"Once married, he lived on his wife's money for two or three years, dining well, sleeping late, smoking big porcel- ain pipes, coming home at night only after the theatres had closed, and spending his days in cafés." (p.7)
"Bunun farkına mı varamadı? Yoksa ona uymayı göze mi alamadı? Her ne hal is ebiz duamızı bitirdikten sonra bile, yeni'nin kasketi hala dizinin üstündeydi." (s. 21)

Fransızca metinde yer alan "diner bien” ifadesi “iyi yemek” anlamına gelmektedir. İngilizce'de de aynı anlama gelen "dining well" ifadesiyle anlam aktarılmış ve kaynak metne bağlı bir aktarım tercih edilmiştir. Türkçe'de ise "yediğine, içtiğine dikkat etmek" anlamında kullanılan "boğazına iyi bakmak" deyimi ile anlam aktarımı sağlanmış ve erek kültüre özgü bir ifade tercih edilmiştir.

Örn. 5. "Et elle la détesta, d'instinct" (Flaubert, 1929, s. 39).

"Instinctively, she loathed her." (p.18) “Kadınlık duygusu ile Emma’ya kin bağladı.” (s. 30)

Fransızca özgün metinde yer alan "ondan içgüdüsel olarak nefret ediyor” cümlesi İngilizce' de de birebir aynı anlama gelen sözcükler ile ifade edilmiştir. Türkçe çeviri de ise "kin bağlamak" deyimi kullanılarak anlam aktarımı sağlanmıştır.

Örn. 6. "Le lendemain, dès neuf heures, il était à la ferme" (Flaubert, 1929, s. 53).

"Next morning he was at the farm by nine." (p.24) $\quad$ "Ertesi sabah saat dokuzda Charles çiftliğe damladı." (s. 34)

Kaynak metinde yer alan “ertesi gün saat dokuzda çiftlikteydi”anlamına gelen cümle İngilizce'de kaynak metnin anlamı korunarak aynı anlam ile "Next morning he was at the farm by nine" (Ertesi sabah saat dokuzda çiftlikteydi.) biçiminde aktarılmıştır. Türkçe'de ise "bir işin yapıldığı sırada gelmek” biçiminde bir anlama sahip "damlamak" sözcüğü ile mecazlı bir anlatım tercih edilmiştir. Bu ifadenin erek kitle için anlaşılır ve uygun bir ifade olduğunu söylemek mümkündür. Çevirmen, ifadeyi değiştirerek mecazlı bir anlam tercih etmiştir.

Örn. 7. “...quelquefois, il lui donnait sur les joues de gros baisers à pleine bouche” (Flaubert, 1929, s. 73). "Sometimes he gave her great smacking kisses on the “...bazen yanaklarından şapur şupur öper.” (s. 41) cheeks..."(p. 32) 
Kaynak metinde yer alan "baiser à pleine bouche" ifadesi "içten ve büyük bir öpücük" anlamına gelmektedir. İngilizce çevirisinde anlam aynı anlama gelen “...great smacking kisses” (içten öpücükler) ifadesi ile aktarılmıştır. Türkçe'de ise kültüre özgü bir ifade olan "şapur şupur öpmek” ifadesiyle anlam erek dil okura sunulmuştur. Erek kitle okuyucularının okurken yabancılık çekmeyeceği bir ifadedir. İngilizce çevirinin kaynak metne bağlı bir çeviri olduğu Türkçe çevirinin ise değiştirilerek kaynak metinden bağımsız özgür bir çeviri olduğu söylenebilir.

Örn. 8. "Elle le charmait par quantité de délicatesses" (Flaubert, 1929, s. 126).

"She enchanted him with countless delicate refinements." (p. 54)

“Emma’da Charles'ın ağzını kulaklarına vardıran binbir incelik vardı." (s. 59)

Özgün metinde "charmer” (hayran bırakmak, büyülemek) fiili kullanılmış, İngilizce çevirisinde ise kaynak metne bağlı bir biçimde aynı anlama gelen "enchant" (hayran bırakmak, büyülemek) fiili ile anlam aktarılmıştır. Türkçe çeviride çevirmen "neşelenmek, mutlu olmak" anlamlarına gelen "ağzı kulaklarına varmak" deyimi ile anlam aktarımını sağlamış ancak çevirmenin tercihi erek dilde kaynak söylemden anlamsal bir uzaklaşmaya neden olmuştur.

Örn. 9. “....ce qui faisait ouvrir de grands yeux à son mari” (Flaubert, 1929, s. 139).

“...views which made her husband's eyes start out of his head in amazement." (p. 60)

Fransızca'da "çok şaşırmak" anlamına gelen "ouvrir de grands yeux" (https://www.larousse.fr/dictionnaires/ francais/yeux/55646\#locution, 01.09.2021) deyimi kullanılmış ve İngilizce'de aynı anlamı verecek sözcükler tercih edilerek aktarım sağlanmıştır. Türkçe'de ise "faltaşı gibi açılmak" deyimi ile erek dilde kültüre özgü bir aktarım gerçekleştirilmiştir.

Örn. 10. “Qu'est- ce qu'il a donc, le père Tellier?” (Flaubert, 1929, s. 215).

"So what's the matter with him, old man Tellier?" $\quad$ "Tellier Babanın da nesi var Allah aşkına.” (s. 91) (p.93)

Kaynak metinde yer alan cümle "öyleyse Tellier babanın nesi var” biçiminde bir anlama gelmektedir. İngilizce'de de aynı anlamda bir cümle ile anlam aktarılmış, ancak baba anlamına gelen "father" sözcügü değil "yaşlı adam” anlamında "old man” sözcükleri kullanılmıştır. Türkçe'de ise çevirmen kültüre özgü bir ekleme yaparak "Allah aşkına” söz öbeğini ilave etmiştir. Erek dil okuyucuları için yabancılık hissi vermeyecek bir biçimde anlam aktarımı tercih edilmiştir.

Örn. 11. “Ces gens-là, madame, n'avaient pas le moindre ordre! il s'est calciné avec l'eau- de-vie!” (Flaubert, 1929, s. 215).

"That sort, Madame, they hadn't a vestige of selfcontrol. He burnt out all his insides with brandy!" (p.93)

Kaynak metinde ve İngilizce çevirisinde yer almayan, "vallahi” sözcüğü metnin Türkçe çevirisine çevirmen tarafından eklenmiştir. Erek kültüre uygun bir sözcük tercih edilmiştir.

Örn. 12. "Mais, moi, reprenait Emma, c'est après le mariage que ça m’est venu” (Flaubert, 1929, s. 225).

“But with me,' replied Emma, 'it was after I got married that it began." (p.98)

"Vallahi hanım efendi bu adamlar düzen, tertip nedir bilmezler!...”(s. 91)

Kaynak metinde yer alan "evlilik" anlamına gelen "le mariage" sözcüğü İngilizce'de de aynı anlamda bir sözcük ile karşılanmıştır. Türkçe'de ise çevirmen anlamı "evlenmek” (Aksoy, 1988, s. 935) anlamına gelen "kocaya varmak" deyimi ile aktarmıştır. Çevirmen kültüre özgü bir ifadeden yararlanmıştır.

Örn. 13. "Comment vous portez-vous? ajouta-t-il

Mal, répondit Emma; je souffre" (Flaubert, 1929, s. 230). 
'How are you keeping?' he went on. 'Not well,'

replied Emma, 'not at all well.” (p.100)
"Nasılsınız, iyisiniz inşallah?

Emma: -Hiç iyi değilim, dedi; 1stırap içindeyim. (s. 97)"

Kaynak metinde "nasılsınız?" anlamına gelen ifade, İngilizce'de de aynı anlama gelen "How are you keeping?" (Nasılsın?) cümlesi ile aktarılmıştır. Kaynak metne bağlı oluşturulan bir cümle olduğu söylenebilir. Türkçe çeviride ise dilimize Arapça'dan giren “İnşallah” (Allah'ın izniyle) ifadesi de eklenerek anlam aktarımı sağlanmıştır. Çevirmen kültüre özgü bir ifade ile anlamı kuvvetlendirmiştir.

Örn. 14. “-Regarde donc, cher ami, lui dit Emma d'une voix tranquille; voilà la petite qui, en jouant, vient de se blesser par terre" (Flaubert, 1929, s. 237).

'Look what's happened, dear,' she said in a calm voice; 'the baby fell while she was playing, she's hurt herself." (p.103)

“Bak, kocacığım, dedi: Çocuk oynarken yere düşüp yüzünü kanattı.” (s. 100)

Fransızca metinde yer alan "sevgilim, canım" anlamlarına gelen "cher ami” ifadesi İngilizce çeviride de aynı anlama gelen "dear” sözcüğü ile aktarılmıştır. Türkçe'de çevirmen değiştirme yaparak "kocacığım” biçiminde bir ifade ile anlam aktarımını sağlamıştır.

Örn. 15. “Adieu, pauvre enfant! adieu, chère petite, adieu!”(Flaubert, 1929, s. 244).

“Goodbye, you sweet little thing! Goodbye, my pet, “Allaha ısmarladık yavrucuğum! Allahaısmarladık goodbye!" (p.106) cicim! Allahaısmarladık!” (s. 103)

Özgün metinde yer alan “elveda” anlamına gelen “adieu” sözcüğü, İngilizce çeviride de aynı anlama gelen “good-bye” (hoşça kal, güle güle, elveda) sözcüğü ile aktarılmıştır. Türkçe'de ise çevirmen kültüre özgü bir ifade kullanarak "Allahaısmarladık” ifadesini kullanmıştır. Çevirmen, kaynak metindeki ifadeyi değiştirerek kültüre özgü uygun bir çeviri yapmıştır. Kaynak metindeki "küçüğüm” anlamına gelen "chère petite" ifadesi, İngilizce'de aynı anlama gelen "sweet little thing" ifadesi ile aktarılmış, Türkçe'de ise "yavrucuğum” biçiminde erek kültüre özgü farklı bir sözcük kullanılarak anlam aktarımı sağlanmıştır.

Örn. 16. "Bon voyage!" (Flaubert, 1929, s. 247).

“Bon voyage!” (p.107) $\quad$ "Hayırlı yolculuklar.” (s. 104)

Fransızca metinde yer alan bir iyi dilek ifadesi, "iyi yolculuklar” ifadesi İngilizce çevirisinde kaynak metindeki biçimiyle korunarak İngilizceye çevirisi yapılmadan “Bon voyage!” biçiminde aktarılmıştır. Türkçe'de ise "hayırlı yolculuklar" biçiminde kültüre özgü bir ifadenin tercih edildiği görülmektedir.

Örn. 17. “Allons, va-t’en! cours! attends-moi, et surveille les bocaux!” (Flaubert, 1929, s. 265).

"Hurry up! Wait for me there, and keep an eye on "Koş! Beni bekle. Şişelere de göz kulak ol.” (s. 111) those jars." (p.115)

Kaynak metinde yer alan “denetlemek, gözlemlemek” anlamında kullanılan “surveiller” sözcüğü, İngilizce'de erek kültüre özgü "gözü üstünde olmak" anlamına gelen "keep an eye on..." deyimi kullanılarak aktarılmıştır. Türkçe çevirisinde de "korunması gereken kimseyi ya da şeyi görüp gözetmek" (Aksoy, 1988, s. 811) anlamında kullanılan "göz kulak olmak" deyimi ile anlam aktarımı sağlanmıştır. Kaynak metin hem İngilizce çevirisinde hem de Türkçe çevirisinde deyimlerden yararlanılarak erek kültürlere uygun olarak aktarılmıştır.

Örn. 18. "Peu à peu, ces craintes de Rodolphe la gagnèrent” (Flaubert, 1929, s. 339).

"As time passed, she came to share Rodolphe's fears." (p.146)

“Rodolphe'un bu endişeleri yavaş yavaş Emmaya'da geçti." (s. 138)

Fransızca'da yer alan “azar azar, yavaş yavaş” anlamlarına gelen "peu à peu” ikilemesi, İngilizce'de "zaman geçtikçe” anlamını veren "as" (-dıkça, -dikçe) bağlacı ile aktarılmıştır. Türkçe'de ise kaynak metne bağlı kalarak çevirmen "yavaş yavaş" ikilemesi ile anlam aktarımını gerçekleştirmeyi tercih etmiştir. Yani çevirmen kaynak metne yakınlık sağlayarak uygun bir aktarım gerçekleştirmiştir.

Örn. 19. "Ma femme! Ma femme! Cria Charles” (Flaubert, 1929, s. 423).

\begin{tabular}{|l|l} 
“Emma! Emma! cried Charles.” (p.183) & "Karıcı̆̆ım, karıcı̆̆ım.” (s. 169)
\end{tabular}


Özgün metin olan Fransızca’da yer alan "ma femme! ma femme!” (karım! karım!) ifadesi İngilizce çevirisinde roman kahramanı Emma'nın adının "Emma! Emma!" biçiminde iki kere tekrar edilmesiyle yer almaktadır. Romanın Türkçe çevirisinde ise özgün metindeki içten duygu daha da pekiştirilerek Türkçe'de yer alan küçültme ekinin kullanımı ile anlam aktarılmışıı. Küçültme ekleri eklendikleri isim, sıfat ya da zamirlerin değerini azaltarak ya da sevgi, acıma ve şefkat yoluyla kü̧̧ülterek, gerçek anlam ve değeri dışında anlamı bir dereceye kadar küçültmüş olmaktadırlar. Burada "karıcığım, karıcı̆ıım" biçiminde yer alan ifadenin sevgi, acıma ve şefkat duygularını içerdiği söylenebilir. Çevirmen anlamı kuvvetlendirmek adına böyle bir anlatımı tercih etmiş ve anlamsal eşdeğerliği bu biçimde sağlamıştır.

Örn. 20. "Et Emma quotidiennement attendait, avec une sorte d'anxiété, l'infaillible retour d'événements minimes, qui pourtant ne lui importaient guère" (Flaubert, 1929, s. 437).

"And every day Emma awaited, with a kind of anxiety, the unvarying recurrence of the same trivial events, little though they mattered to her." (p. 188)
“Emma, Allah'ın günü kendisince pek ehemmiyeti olmayan ufak tefek olayların şaşmaz bir intizamla vukuunu bir çeşit endişe içinde bekliyordu." (s. 174175)

Özgün metinde geçen "her gün, günlük ve gündelik" gibi anlamlara gelen “quotidiennement” sözcüğü, İngilizce çevirisinde aynı anlama gelen "everyday” sözcügü ile karşılanmıştır. Türkçe çevirisinde ise sözcügün kelime anlamı kullanılmamış “hemen hemen her gün” anlamına gelen “Allah’ın günü” deyimi ile anlam aktarımı sağlanmıştır. Metinsel bağlamda düşünüldüğü ve erek kitle için doğru bir deyimin tercih edildiği görülmektedir. Çevirmen tarafından kültürel bir uyarlama gerçekleştirilmiştir.

Örn. 21. "Il y avait le Pensez-y bien; l'Homme du monde aux pieds de Marie, par M. de ***, décoré de plusieurs ordres; Des Erreurs de Voltaire, à l'usage des jeunes gens, etc.” (Flaubert, 1929, s. 441).

"There were such titles as: Weigh It Well; The Man of the World at the Feet of Mary, by Monsieur de***, Knight of $* * *$, Honorand of***; The Errors of Voltaire, Designed for the Edification of Youth; etc." (p. 190)
“Aralarında, iyi düşünün; Hz. Meryem'in ayaklarına kapanan hovarda müellifi birçok nişanla taltif edilmiş Mösyö de..., gençlerin istifadesi için Voltaire'in hataları vb. kabilinden eserler vardır." (s.175-176).

Fransızlar "Hz. Meryem" için "Vierge Marie" ya da "Marie" biçiminde adlandırmalar kullanırlar. Aynı biçimde İngilizler de Hz. Meryem'i "Virgin Mary" ya da "Mary" olarak adlandırırlar. Arapçadan dilimize giren "Hazret" sözcüğü Türkçe’de sayın, muhterem gibi anlamlara sahiptir. Bu sözcük, İslamiyet inancında peygamber, sahabeler ve veli insanlar için saygı anlamında ismin önünde kullanılan bir sözcüktür. Çevirmenlerin kaynak metinde "Marie" diye geçen ismi "İngilizce" çevirisinde "Mary", Türkçe çevirisinde "Hz. Meryem" biçiminde her kültürün kendi erek dil okuyucuları için anlaşılır olacak düzeyde aktardıkları görülmektedir. Yani çevirmenler kendi kültürlerine göre bir uyarlama yapmayı tercih etmişlerdir.

Örn. 22. "Allons, bon voyage! leur dit-i1, heureux mortels que vous êtes!” (Flaubert, 1929, s. 453).

"Have a good journey, you lucky people! he told them." (p.195)
"Haydi bakalım, iyi yolculuklar Allah'ın sevgili kulları." (s. 180)

Kaynak metinde yer alan "heureux mortels que vous êtes" (siz mutlu ölümlüler) biçiminde yer alan iyi dilek anlamında kullanılan ifade İngilizce'de "you lucky people" (siz mutlu insanlar) biçiminde aynı anlamda aktarılmıştır. Türkçe'de metinsel bağlama uygunluk olarak ifade değiştirilerek "Allah'ın sevgili kulları" biçiminde çevrildiği görülmektedir. Çevirmen tarafından dilimize daha yakın olması ve duyguları daha iyi aktarması nedeniyle böyle bir ifadenin tercih edildiği düşünülmektedir.

Örn. 23. "Et sur le port, au milieu des camions et des barriques, et dans les rues, au coin des bornes, les bourgeois ouvraient de grands yeux ébahis devant cette chose si extraordinaire en province, une voiture à stores tendus, et qui apparaissait ainsi continuellement, plus close qu'un tombeau et ballottée comme un navire" (Flaubert, 1929, s. 504). 
"And the local folk down by the harbour, among the wagons and the big barrels, or walking along the streets or standing at the corners, all stared wide-eyed in astonishment at this spectacle unheard of out- side the capital: a cab with drawn blinds that constantly reappeared, sealed up tighter than a tomb and tossing like a ship." (p.217)
"Limanda yük arabalarıyla variller arasında, sokaklarda, sınır taşlarının bulunduğu köşelerde, șehirliler, küçük perdeleri inik bir arabanın, bir mezar gibi sımsıkı kapalı ve bir gemi gibi bocalaya bocalaya, durmamacasına aynı yerlerden geçmesi gibi taşrada benzeri görülmemiş bir hadiseye afallamış gözlerini dört açarak bakıyorlard1." (s.201)

Fransızca özgün metinde çok şaşırmak anlamında kullanılan "ouvrir de grands yeux” deyimi (https://www. larousse.fr/dictionnaires/francais/yeux/55646\#locution, 01.09.2021) için İngilizce çevirisinde “....all stared wide-eyed in astonishment..." biçiminde şaşırarak merakla bakmak anlamında kullanılan bir ifade yer almaktadır. Türkçe çevirisinde ise "gözlerini dört açarak bakmak" anlamında kullanılan bir deyim ile anlam aktarımının sağlandığı görülmektedir. Çevirmen, Türkçe’de kaynak metne bağlı kalarak deyim ile ifade edilen anlamı yine aynı anlamı içeren bir deyim kullanarak aktarmıştır.

Örn. 24. "-Non, laissez-moi! reprenait l’apothicaire, laissez-moi! fichtre! Autant s’établir épicier, ma parole d'honneur!" (Flaubert, 1929, s. 509).

"Leave me alone! continued the apothecary, 'leave me alone! Hell! I might just as well be a grocer, yes, damn it all, a grocer! Come on!" (p.219)

"-Hayır, diyordu; bırakın beni, bırakın beni. Vay canına, vallahi! Vallahi bakkal olsaymışım daha iyiymiş." (s. 203)

Kaynak metinde yer alan "ma parole d'honneur" deyimi (https://www.larousse.fr/dictionnaires/francais/ yeux/55646\#locution, 01.09.2021) “sözüm bir güvence, bir itimat” anlamlarına gelmektedir. Bu deyim İngilizce çevirisinde deyimin anlamını karşılayacak "I might just as well be a grocer, yes, damn it all, a grocer! Come on!” (Bakkal da olabilirim, evet kahretsin, bakkal! Haydi!) biçiminde bir cümle tercih edilerek aktarılmıştır. Türkçe çevirisinde ise "vallahi” sözcüğü ile anlam aktarımı sağlanmış ve çevirmen tarafından kültürel uyarlama gerçekleştirilmiştir. Burada erek kültüre özgü bir ifade kullanıldığı görülmektedir. Ayrıca hayret edişindeki duyguyu aktarabilmek için Türkçede yer alan "vay canına” ünlemi de yine bir kültürel ifade olarak değerlendirilebilir. Ana dili Türkçe olan bir kişi bu cümleyi okuduğunda kendi kültürüne özgü bir cümle okuduğu hissine sahip olacaktır.

Örn. 25. "Dès le lendemain, elle s'embarqua dans l'Hirondelle pour aller à Rouen consulter M. Léon, et elle y resta trois jours" (Flaubert, 1929, s. 524).

"The very next morning she set off in the Hirondelle for Rouen, to consult Monsieur Léon; she remained there for three days." (p.226)

"Daha ertesi sabah Emma, Rouen'e gidip Mösyö Léon'a akıl danışmak için Kırlangıç'a bindi: orada üç gün kaldı." (s. 209)

Özgün metinde Fransızca danışmak anlamına gelen "consulter” fiili, İngilizce çevirisinde kaynak metne bağlı kalarak çevirmen tarafından aynı anlama gelen "consult” (danışmak) sözcüğü ile aktarılmıştır. Türkçe çevirisinde ise "akıl danışmak" deyimi kullanılarak erek dilde ifade edildiği görülmektedir. Çevirmenin metinsel bağlam düşünüldüğünde yerinde ve uygun bir deyim tercih ettiği söylenebilir.

Örn. 26. "Homais se délectait. Quoiqu'il se grisât de luxe encore plus que de bonne chère..." (Flaubert, 1929, s. 571).

"Homais was revelling in it all. Although he was intoxicated by the luxurious surroundings rather than by the fine fare..." (p.248)

Kaynak metinde yer alan "se griser" fiili “çakırkeyf olmak, sarhoş olmak” anlamlarına gelmektedir. Romanın İngilizce çevirisinde aynı anlama gelen "intoxicate" (sarhoş olmak, kendinden geçmek) fiili tercih edilirken, Türkçe çevirisinde "kendinden geçmek, sarhoş olmak, beğenmek" anlamlarında kullanılan "mest olmak" deyimi ile anlam aktarılmıştır. Çevirmen erek kitlenin anlayacağı bir deyim ile anlamı aktarmayı uygun görmüş ve Türkçe'ye özgü bir ifade ile anlam aktarımını gerçekleştirmiştir.

Örn. 27. “-Ah! mon Dieu! la robe, prenez garde! s’écria madame Lefrançois. Aidez-nous donc! disait-elle au pharmacien. Est-ce que vous avez peur, par hasard?” (Flaubert, 1929, s. 676). 


"Oh, God! Her dress, be careful of her dress!
exclaimed Madame Lefrançois. 'Come on, give us
a hand!' she urged the pharmacist. 'Perhaps you're
scared to?" (p.295)

“-Ah, yarabbi! Elbisesi, dikkat edin elbiseye! diye bağırdı. -Eczacıya dönerek- Bize yardım etsenize, dedi. Yoksa korkuyor musunuz?" (s. 270)

Kaynak metinde yer alan “aman Tanrım” anlamına gelen “mon Dieu” ifadesi, İngilizce' de de aynı anlamda kullanılan "God" (Tanrım) sözcügü ile aktarılmıştır. Türkçe'de ise "Yarabbi” biçiminde erek kültüre özgü bir ifade ile anlam aktarımı sağlanmıştır.

Örn. 28. “-Ah! ma pauvre maîtresse! ma pauvre maîtresse!” (Flaubert, 1929, s. 676).

“Oh, my poor mistress! My poor mistress!” (p. 295) “-Ah, zavallı hanımcığım! Zavallı hanımcı̆̆ım!” (s. 269)

Fransızca özgün metinde yer alan "zavallı hanımım” anlamında kullanılan "ma pauvre maitresse" ifadesi İngilizce çeviride aynı anlama gelen "my poor mistress" (zavallı hanımım) biçiminde edilmiştir. Türkçe'de ise yine aynı anlamda sözcükler tercih edilmiş fakat küçültme ekiyle "acıma, üzülme ve şefkat” duygularını içeren "hanımcığım" ifadesi de kullanılmıştır.

Örn. 29. “-Ma fille! Emma! mon enfant! expliquez- moi...” (Flaubert, 1929, s. 685).

"My daughter! Emma! My child! Please, tell me...” “Kızım, Emmacığım, yavrum! Anlatın bana.”(s.273) (p.299)

Özgün metinde "kızım, Emma, çocuğum” biçiminde yer alan cümle, İngilizce'de birebir aynı anlama gelen "My daughter! Emma! My child!” (Kızım Emma, çocuğum!) sözcükleri kullanılarak aktarılmıştır. Türkçe'de ise erek kültüre bir uyarlama söz konusudur. Çevirmen değiştirerek küçültme ekiyle kullanılan özel isim ve ardından içtenlik, şefkat duygularının yer aldığı yavrum sözcüğü ile aktarımı sağlamıştır.

Örn.30. "Mais l'aubergiste ne l'écoutait que d'une oreille, ayant comme lui des chagrins” (Flaubert, 1929, s. 709).

"But the innkeeper only listened with half an

ear..."(p.310)

"Fakat han sahibesi, kendisi de dertli olduğu için onu yarım kulakla dinliyordu." (s. 281)

Fransızca metinde yer alan "écouter que d'une oreille” (tek kulak ile dinlemek), bir deyimdir. İngilizce'de "listened with half an ear" (yarım kulakla dinlemek) ve Türkçe'de de "yarım kulak dinlemek” biçiminde yine aynı anlamlara gelen deyimler ile anlam aktarılmıştır. Yani her çevirmen kendi kültürüne özgü bir deyim ile erek kitle için anlaşılırlığı sağlamıştır. Kültürel uyarlamayı gerçekleştirerek kaynak metne bağlı bir anlam aktarımı sağlanmıştır.

\section{Sonuç}

Çeviri, kaynak dildeki metnin ve ifadelerin doğru anlaşılıp erek dile uygun yeniden yorumlanması işidir. Amaç, anlamı kaynak dilden çözmek ve erek dilde yeniden yorumlamak, ifade etmektir. Çevirmen ise benzerlikleri ve farklılıkları göz önünde bulundurarak çeviri eylemini gerçekleştirmelidir. Çevirmen, her iki dilin sahip olduğu dilsel özellikleri bilmeli, deyim, atasözü gibi kalıplaşmış ifadeleri doğru çözümleyebilmelidir. Çeviri dil ve kültür olmak üzere iki önemli boyuta sahiptir. Bundan dolayı çevirmenin de iki dilli ve iki kültürlü olması beklenir. Çevirmen, her iki dilin dilsel yapılarını ve sözcüklerinin kullanımını doğru kavramış olmalı ve kaynak metin ifadelerini tam olarak anlamalı erek dile aktarabilecek yaratıcılığa da sahip olmalıdır. 
Bu çalışma dilin kültürden bağımsız düşünülemeyeceğinin mümkün olmadığını eşdeğerlik kuramı çerçevesinde ortaya koymaktadır. Ayrıca eşdeğerlik kuramının çevirmenin erek normlara göre çeviri yapması açısından çevirmene yol gösterici bir niteliğe sahip olduğu sonucuna da varılmıştır.

Bu çalışmada, eşdeğerlik kavramına bağlı olarak Madame Bovary adlı romanın Fransızca aslı İngilizce ve Türkçe çevirileri ile karşılaştırmalı bir biçimde incelenmektedir. Seçilmiş örnekler üzerinden ifadelerin kaynak metindeki anlamı aynı biçimde ya da kültürel uyarlamalar ile yapıldığı gözlemlenmektedir. Çeviri metinler ile özgün metin karşılaştırıldığında anlamsal eşdeğerlik sağlanırken genel olarak kültürel farklılıklardan kaynaklanan birtakım değişiklikler olduğu gözlemlenmektedir. Çevirmenlerin her kültürün erek okuyucuları tarafindan daha anlaşılır olacak biçimde kendilerine özgü ifadeler ile anlam aktarımını gerçekleştirdikleri görülmektedir. Dolayısıyla öncelikli amacın anlaşılır bir çeviri yapabilmek olduğu ve bu doğrultuda da çevirmenler tarafından çeviri eylemi gerçekleştirildiği söylenebilir. Kaynak kültürden erek kültürlere gerçekleştirilen aktarımlarda önceliğin anlamsal eşdeğerliğin sağlanmasına verilerek erek dil okuyucuları için yabancılık hissi uyandırmayan ifadelerle kendi kültürüne özgü metinler okuyormuşçasına bir dil kullanımı tercih edildiği gözlemlenmektedir. Ayrıca romanın İngilizce çevirisinde genel olarak kaynak metne sadık bir aktarım gerçekleştirilirken, Türkçe çevirisinde daha çok kültürel uyarlamanın tercih edildiği tespit edilmektedir. İngilizce çevirisinin kaynak dizge geleneğine yakın bir eşdeğerlik, Türkçe çevirisinin ise erek dizge geleneğine yakın bir eşdeğerlik ile oluşturulduğunu söylemek mümkün olur.

Hakem Değerlendirmesi: Dış bağımsız.

Yazar Katkıları: Çalışma Konsepti/Tasarım- ; Veri Toplama- ; Veri Analizi/Yorumlama- ; Yazı Taslağı- ; İçeriğin Eleştirel İncelemesi- ; Son Onay ve Sorumluluk-

Çıkar Çatışması: Yazarlar çıkar çatışması bildirmemiştir.

Finansal Destek: Yazarlar bu çalışma için finansal destek almadığını beyan etmiştir.

Peer-review: Externally peer-reviewed.

Author Contributions: Conception/Design of Study- ; Data Acquisition- ; Data Analysis/Interpretation- ; Drafting Manuscript- ; Critical Revision of Manuscript- ; Final Approval and Accountability-

Conflict of Interest: The authors have no conflict of interest to declare.

Grant Support: The authors declared that this study has received no financial support.

\section{KAYNAKÇA/REFERENCES}

Aksoy, Ö. A. (1988). Atasözleri ve Deyimler Sözlüğü. İstanbul: İnkılap Kitabevi.

Aksoy, B. (2002). Geçmişten Günümüze Yazın Çevirisi. Ankara: İmge Kitabevi.

Baker, M. (1992). In Other Words: A Coursebook On Translation. USA and Canada: Routledge.

Boztaş, İ. (1992). Çeviri, Çeviride Eşdeğerlilik ve Dilbilim, Dilbilim 20. Yıl Yazıları. Ankara: Karaca Dil Kursu Yayınları.

Catford, J. (1965). A Linguistic Theory of Translation. Çeviribilim ve Uygulamaları Dergisi.

Çavuş, G. (2005). Kaynak-Odaklı ve Erek-Odaklı Çeviri Yaklaşımlarında Eşdeğerlik Sorunu. Mersin: Mersin 
Üniversitesi Sosyal Bilimler Enstitüsü Çeviri Anabilim Dalı, Yayımlanmamış Yüksek Lisans Tezi.

Flaubert, G. (1929). Madame Bovary. Paris: La Bibliothèque électronique du Québec.

Flaubert, G. (1966). Madame Bovary. İstanbul: Türkiye İş Bankası Yayınları.

Flaubert, G. (2004). Madame Bovary. (M. (. Mauldon, Çev.) Oxford University Press.

Jakobson, R. (1959). On Linguistic Aspects of Translation . On Translation (s. 232-239). içinde New-York.

Köksal, D. (2008). Çeviri Eğitimi/Kuram ve Uygulama. Ankara: Nobel Yayın Dağıtım.

Kuran, N. P. (1993). Kültürlerarası İletişim Aracı Olarak Çeviri. İstanbul: Boğaziçi Üniversitesi Yayınları.

Lederer, M. (1994). La Traduction Aujourd'hui. Paris: Hachette.

Newmark, P. (1988). A Textbook of Translation. Prentice Hall International (UK) Ltd.

Nida, E. A. (1964). Towards a Science of Translating. Liden: E.J: Brill.

Nord, C. (2008). La traduction: Une Activité Ciblée Introduction Aux Approches Fonctionnalistes. Arras: Artois Presses Université.

Suçin, M. H. (2007). Öteki Dilde Var Olmak. İstanbul: Multilingual. İstanbul: Multilingual.

Toury, G. (1980). In Search of a Theory of Translation. Tel Aviv, The Porter Institue for Poetics and Semiotics:

Tel Aviv University.

Vardar, B. (1981). Çeviri Konuşmaları. Yazka Çeviri(2), 172-173.

Vinay, J. P., \& Darbelnet, J. (1995). Comparative Stylistics of French and English. (M. J. Juan C. Sager, Çev.)

Amsterdam / Philadelphia: John Benjamins Publishing Company.

Wills, W. (1977). Übersetzungswissen schaft, Probleme und methode. Stuttgart.

\section{İnternet Kaynakları}

https://www.larousse.fr/dictionnaires/francais/yeux/55646\#locution. (01.09.2021)

https://idioms.thefreedictionary.com/My+Word. (01.09.2021). 
